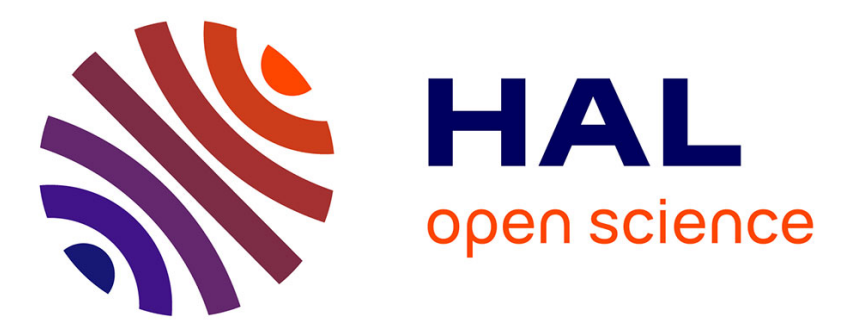

\title{
SIMS Analyses Applied to Open an Optical Window in 4H-SiC Devices for Electro-Optical Measurements
}

Mihai Lazar, François Jomard, Duy Minh M Nguyen, Christophe Raynaud, Gontran Pâques, Sigo Scharnholz, Dominique Tournier, Dominique Planson

\section{- To cite this version:}

Mihai Lazar, François Jomard, Duy Minh M Nguyen, Christophe Raynaud, Gontran Pâques, et al.. SIMS Analyses Applied to Open an Optical Window in 4H-SiC Devices for Electro-Optical Measurements. Materials Science Forum, 2012, 717-720, pp.885-888. 10.4028/www.scientific.net/MSF.717720.885 . hal-02166414

\section{HAL Id: hal-02166414 https://hal.science/hal-02166414}

Submitted on 26 Jun 2019

HAL is a multi-disciplinary open access archive for the deposit and dissemination of scientific research documents, whether they are published or not. The documents may come from teaching and research institutions in France or abroad, or from public or private research centers.
L'archive ouverte pluridisciplinaire HAL, est destinée au dépôt et à la diffusion de documents scientifiques de niveau recherche, publiés ou non, émanant des établissements d'enseignement et de recherche français ou étrangers, des laboratoires publics ou privés. 


\title{
SIMS analyses applied to open an optical window in $4 \mathrm{H}-\mathrm{SiC}$ devices for electro-optical measurements
}

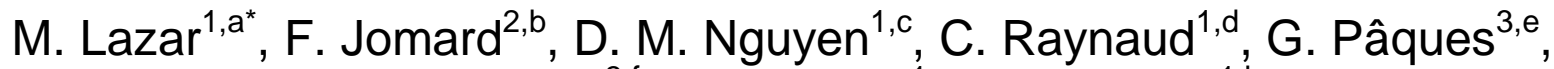 \\ S. Scharnholz $z^{3, f}$, D. Tournier ${ }^{1, g}$, D. Planson ${ }^{1, h}$ \\ ${ }^{1}$ Université de Lyon, CNRS, INSA-Lyon, Laboratoire AMPERE, UMR 5005, F-69621 Villeurbanne \\ Cedex, France \\ ${ }^{2}$ Université de Versailles-Saint-Quentin, CNRS, Laboratoire GEMAC, UMR 8635, F-92195 Meudon \\ Cedex France \\ ${ }^{3}$ French-German Research Institute of Saint Louis (ISL), 5 rue du Général Cassagou, F-68301 \\ Saint Louis Cedex, France \\ amihai.lazar@insa-lyon.fr, ${ }^{\text {b francois.jomard@cnrs-bellevue.fr, }{ }^{c} d u y-m i n h . n g u y e n @ i n s a-l y o n . f r, ~}$ \\ dchristophe.raynaud@insa-lyon.fr, 'gontran.paques@rwth-aachen.de, 'sigo.scharnholz@isl.eu, \\ ${ }^{9}$ dominique.tournier@insa-Iyon.fr, ${ }^{\text {h}}$ dominique.planson@insa-Iyon.fr, "corresponding author
}

Keywords: 4H-SiC, SIMS, OBIC, optical window, impact ionization coefficients, bipolar diode.

\begin{abstract}
H-SiC vertical bipolar power diodes have been fabricated with bilayer metallic anode contact based on an Al-Ti-Ni ohmic contact and a thick Al over-metallization. An optical window of $100 \times 100 \mu \mathrm{m}^{2}$ has been created through the anode contact with a SIMS Cameca IMS 4F equipment using $\mathrm{Cs}^{+}$primary ions at $10 \mathrm{kV}$ and with a beam spot size of $500 \mathrm{~nm}$. The current/voltage characteristics of the diodes show that the SIMS process does not induce an increase of the leakage currents in forward nor in reverse bias. OBIC UV photogeneration occurs under the optical window and not under the contact metal.
\end{abstract}

\section{Introduction}

Wide bandgap semiconductors and silicon carbide materials in particular are very promising for high temperature, high-power and high-frequency device applications. In order to reduce the fabrication cost by decreasing the on-state resistance and the thickness of the epitaxial layers, the two epitaxial layer parameters, thickness and doping level, must be optimized for a projected blocking voltage, like the n-base in high voltage devices [1]. Device structure design needs an understanding of the avalanche mechanism in reverse biased junctions with a precise determination of the impact ionization coefficient in the required electrical field range.

To understand the avalanche mechanism in the reverse biased junction, Optical Beam Induced Current (OBIC) is a suitable method that enables to extract the ionization coefficients [2,3]. During OBIC measurements, an UV laser beam has to penetrate in the SiC epilayer close to the junction under the metallization contact. Thus, an optical window is needed through the contact metallization on the surface which could be the anode contact in the case of vertical bipolar diodes.

We propose and demonstrate in this paper a simple method to open this window on SiC vertical bipolar devices. This method can be extended to other wide band-gap semiconductors like diamond or other hard technological materials.

Extraction of impact ionization coefficients using OBIC requires a breakdown in the bulk of the main junction under the avalanche mode. Therefore, the lateral protection such as mesa and/or JTE, but also the optical window, must be accurately designed and fabricated [4]. In general, an optical window in the anode is realized by photolithography patterns. With this method we have realized several runs of $\mathrm{SiC}$ diodes and frequently we had difficulty in obtaining bulk breakdown in the avalanche mode. We therefore propose an alternative method that could be useful in specific cases, in particular by enabling us to focus on the geometry of the lateral periphery of the vertical power devices. 
Our method adopts Secondary Ion Mass Spectrometry (SIMS) analyses to open, locally, the contact metallization as a technological step in device fabrication for OBIC.

Moreover, the real time analyses of the SIMS spectra enables an accurate definition of the etching process at the metal/SiC interface, which may be critical when thin junctions are created in the surface by low energy ion implantation.

\section{Experimental}

Vertical bipolar power diodes have been fabricated on a commercial $n^{+} 4 \mathrm{H}-\mathrm{SiC}$ substrate with an n-type drift and a top p-type anode-epilayer. Details on the fabrication process have been published elsewhere [5]. Ohmic contacts for the anode have been realized in two steps: first, by patterning followed by a rapid thermal annealing a $250 \mathrm{~nm}$ layer, based on $\mathrm{Al}$, $\mathrm{Ti}$ and $\mathrm{Ni}$, and secondly, by adding a $500 \mathrm{~nm}$ thick Al over-metallization on top of the contacts. The diodes have a circular geometry with a diameter of $1 \mathrm{~mm}$ (Fig. 1).

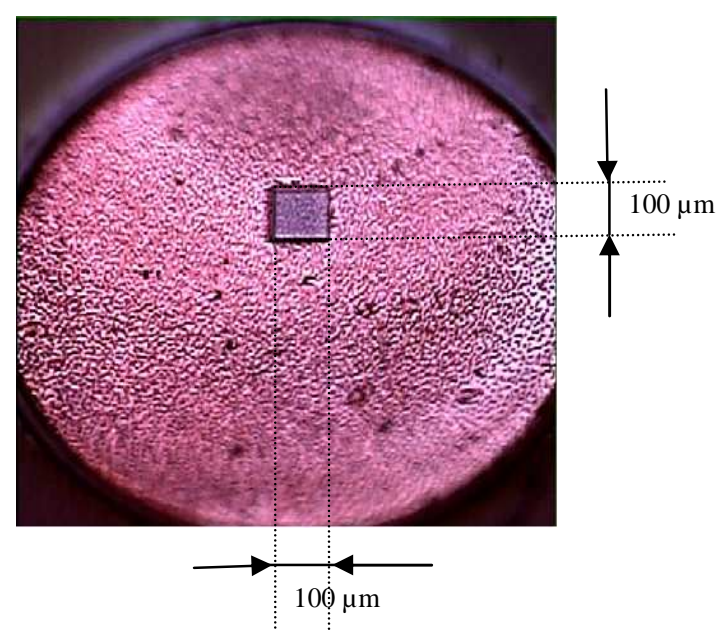

(a)

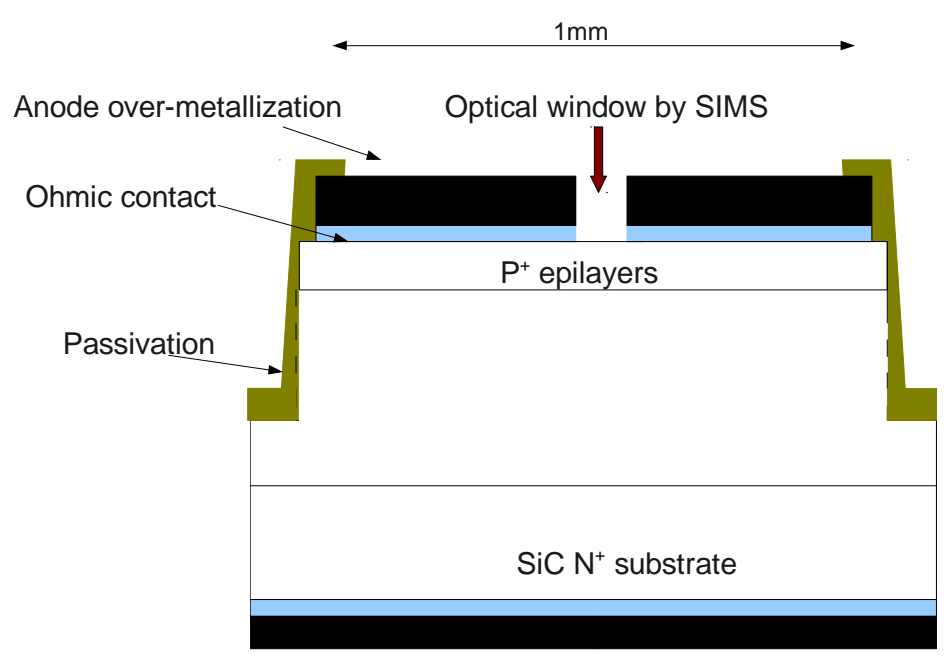

(b)

Fig. 1. A surface crater created by SIMS into the metallization of a vertical bipolar diodes: micrograph image of the crater (a) and the coss-section of the vertical bipolar diode $(b)$.

The optical window has been opened with a SIMS Cameca IMS 4F equipment [6]. $\mathrm{Cs}^{+}$primary ions have been accelerated at $10 \mathrm{kV}$, the impact energy was $14.5 \mathrm{keV}$ and the spot size of the beam was $500 \mathrm{~nm}$. As shown in Figure 1 the crater (created) on the surface by the scanned $\mathrm{Cs}^{+}$primary ion beam is well defined with vertical sides, and is about $100 \times 100 \mu \mathrm{m}^{2}$ large. In order to avoid side contamination effects, the SIMS analyzed zone is smaller with a diameter of about $30 \mu \mathrm{m}$.

Finally, I-V current/voltage measurements and OBIC analyses have been performed.

\section{Results and discussion}

The SIMS spectra obtained on the diode from Figure 1 is presented in Figure 2. The total depth (of the crater) measured with a stylus profilometer, is $0.98 \mu \mathrm{m}$. In Figure 2, we remark the stripping of the different metal layers, with the $\mathrm{Al}$ over-metallization at the top surface, the intermediate $\mathrm{Al}, \mathrm{Ti}$ and $\mathrm{Ni}$ ohmic contact interface and finally the $\mathrm{SiC}$ epilayer corresponding to the flat $\mathrm{C}^{12}$ and $\mathrm{Si}^{28}$ profiles.

Figure 3 presents typical electrical I-V current/voltage characteristics of the diodes in forward and reverse bias at room temperature, before and after the SIMS process. These characteristics have not a significant evolution, concluding that the SIMS process does not induce an increase of the leakage currents in forward or reverse bias. The same forward current is obtained at $3 \mathrm{~V}$ and the avalanche breakdown of the p-n junction occurs at the same reverse bias voltage. In Ref. [5] we 
have shown that the avalanche multiplication is the main breakdown mechanism in this kind of device and that the positive temperature coefficient is very weak.

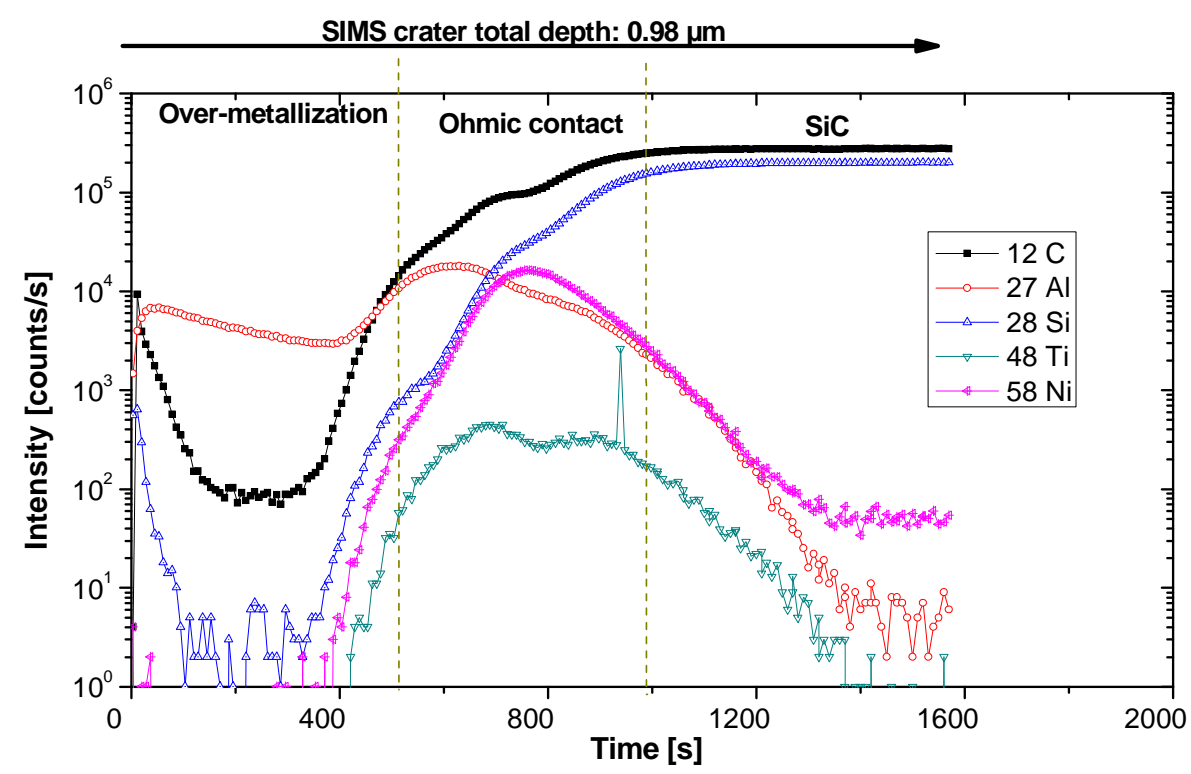

Fig. 2: SIMS elementary spectra of the anode contact metallization through the three zones: overmetallization, ohmic-contact interface and the front of SiC epilayer.

OBIC measurements have been performed on these diodes with an UV laser beam $(351 \mathrm{~nm})$ with a spot size of $3 \mu \mathrm{m}$ diffusing through the cratering formed by SIMS. Figure 4 presents the OBIC photocurrent obtained at 0 and $-50 \mathrm{~V}$ in reverse bias polarization. It is clearly demonstrated that photogeneration occurs under the optical window created by the SIMS crater and not under the metal layer enclosing this crater. This is a crucial point for OBIC technique. This result validates our method of opening of a window in the metal layer using a SIMS analysis.

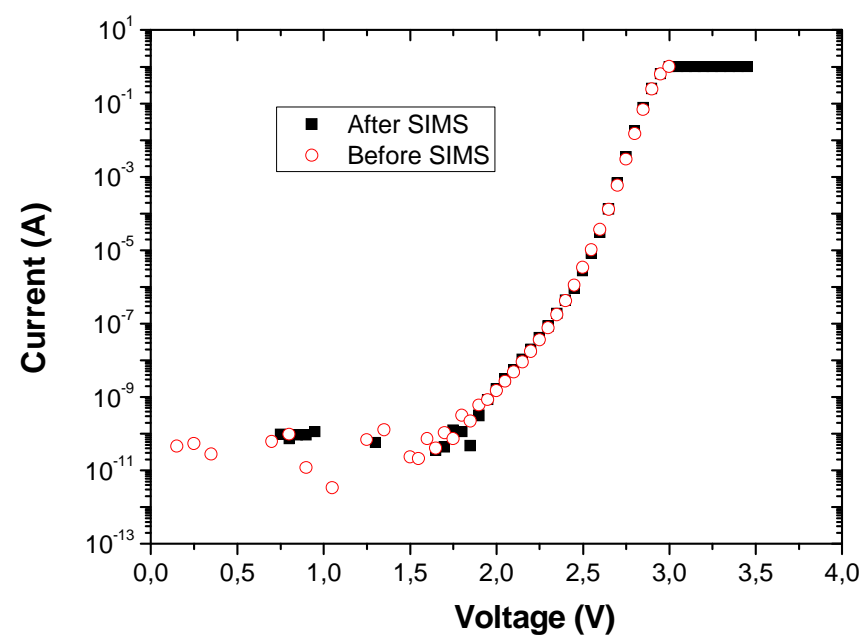

(a)

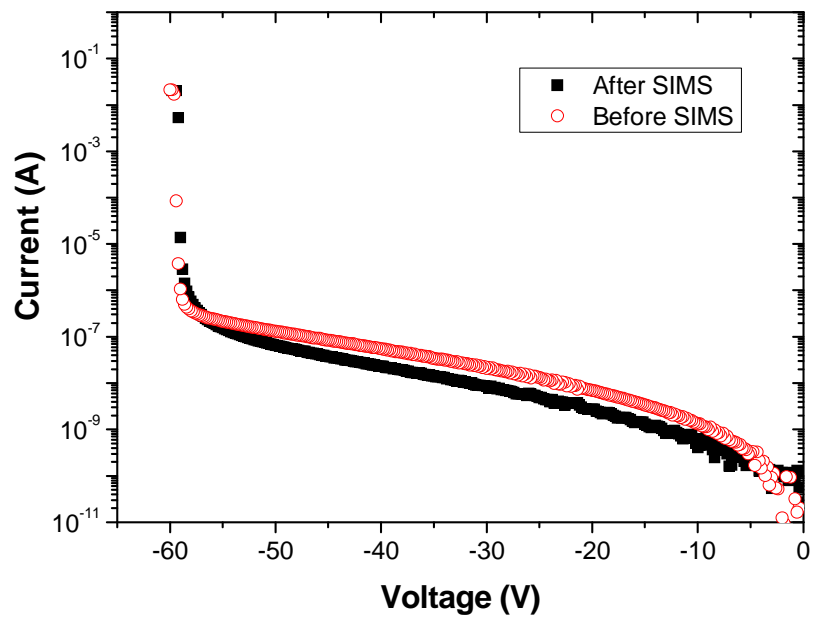

(b)

Fig. 3. Current/voltage characteristics of the diode compared before and after SIMS in forward (a) and reverse (b) bias.

As an ultimate proof for the suitability of this method, the experimental extraction of the impact ionization coefficients in $4 \mathrm{H}-\mathrm{SiC}$ has been performed from OBIC analyses on these diodes with an optical window opened by SIMS. More details on these results are presented in another paper in this conference [7]. 


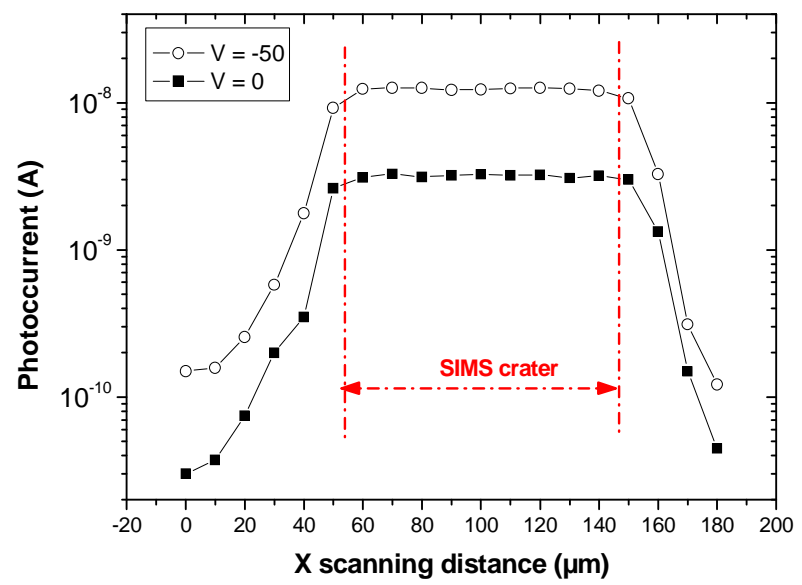

\author{
Figure 4. OBIC photocurrent \\ linear scanning obtained at 0 \\ and $-50 \mathrm{~V}$ in reverse bias \\ polarization on the window \\ opened by SIMS
}

\title{
Summary
}

We propose and demonstrate in this paper a simple method of opening a window on $\mathrm{SiC}$ vertical bipolar devices. This enables to study experimentally the avalanche mechanism in reverse biased junction by electric-optical measurements. Our method consists in using SIMS analyses to locally open the contact metallization as a technological step with the $\mathrm{Cs}^{+}$primary ion beam by stopping accurately the etching process at the metal/SiC interface. The SIMS process does not induce an increase of the leakage currents in forward or reverse bias on the bipolar diodes we studied. OBIC measurements performed on these diodes with an UV laser ray clearly demonstrated photogeneration under the optical window and not under the metal layer. The photocurrent evolution with the diode reverse bias enables extraction of the impact ionization coefficients.

\section{Acknowledgements}

The financial support by the National Agency for Research (fr: Agence Nationale de la Recherche, ANR,) is gratefully acknowledged by the authors.

\section{References}

[1] W. Bartsch, R. Schoerner, K. O. Dohnke, Optimization of Bipolar SiC-Diodes by Analysis of Avalanche Breakdown Performance, Mat. Sci. Forum 645-648 (2010) 909-912.

[2] D.M. Nguyen, C. Raynaud, N. Dheilly, M. Lazar, D. Tournier, P. Brosselard and D. Planson, Experimental determination of impact ionization coefficients in 4H-SiC, Diam. Relat. Mater. 20 Issue 3 (2011) 395-397.

[3] C. Raynaud, D.M. Nguyen, N. Dheilly, D. Tournier, P. Brosselard, M. Lazar and D. Planson, Optical beam induced current measurements: principles and applications to $\mathrm{SiC}$ devices characterization, Phys. Status Solidi A 206 (2009) 2273-2283.

[4] K. Isoird, M. Lazar, M.-L. Locatelli, C. Raynaud, D. Planson and J.-P. Chante, Study of 4H$\mathrm{SiC}$ high voltage bipolar diodes under reverse biases using electrical and Obic characterization, Mat. Sci. Forum, 389-393 (2002) 1289-1292.

[5] D.M. Nguyen, G. Pâques, N. Dheilly, C. Raynaud, D. Tournier, J. P. Konrath, S. Scharnholz, D. Planson, Avalanche diodes with low temperature dependence in 4H-SiC suitable for parallel protection, Mat. Sci. Forum 679-680 (2011) 567-570.

[6] T. Kociniewskid, Homoepitaxie et dopage de type $\mathrm{n}$ du diamant, Thesis $(\mathrm{PhD})$, University of Versailles Saint-Quentin-en-Yvelines, (2006) 54-58. Information on: tel.archives-ouvertes.fr.

[7] D.M.Nguyen, C. Raynaud, M. Lazar, N. Dheilly, G. Pâques, D. Tournier, and D. Planson, OBIC measurements on avalanche diodes in $4 \mathrm{H}-\mathrm{SiC}$ for the determination of impact ionization coefficients, ICSCRM 2011, Cleveland, Ohio, USA (2011). 